\title{
La manifiesta ilegalidad de los actos administrativos
}

\author{
por \\ MANUEL FRANCISCO CLAVERO AREVALO \\ Catedrático de Derecho Administrativo de la Universidad de Sevilla
}

Sumario: 1 . Un concepto que adquiere relevancia: la manifiesta ilegalidad.-2. Suspensión de acuerdos de las Entidades locales por manifiesta ilegalidad. - 3. La advertencia de ilegalidad.-4. La revocación de actos administrativos declaratorios de derechos en caso de manifiesta ilegalidad.-5. El allanamiento en la jurisdicción contencioso-administrativa. -6 . Concepto y juicio de esta modalidad de las ilegalidades administrativas.

1. UN CONCEPTO QUE ADQUIERE RELEVANCIA: LA MANIFIESTA

ILEGALIDAD

Desde poco tiempo a esta parte puede decirse que viene prosperando en la terminología de la legislación administrativa española la expresión de "manifiesta ilegalidad». El término viene, por lo general, referido a los actos administrativos, y con él se quiere especificar un grado más acentuado de ilegalidad de la que suelen, a veces, adolecer los actos administrativos.

La ilegalidad de los actos administrativos venía, hasta ahora, siendo tratada a través de cada uno de los defectos de los elementos de los actos administrativos. Le distinguía, a lo más, entre los vicios de legalidad determinadores de nulidad de los actos y los que producían la simple anulabilidad de los mismos. 
Podíx, pues, matizarse entre una ilegalidad, excepcional casi, productora de nulidad, y otra ilegalidad, más frecuente, productora de anulabilidad.

La ilegalidad manifiesta, a la que dedicamos este trabajo, constituye un concepto distinto. La contraposición entre ilegalidad manifiesta e ilegalidad no manifiesta no puede identificarse con la distinción que antes señalábamos entre ilegalidad productora de nulidad e ilegalidad productora de anulabilidad. Cabe perfectamente que una ilegalidad manifiesta produzca tan sólo anulabilidad, y viceversa.

Sirvan como ejemplo de la extensión del concepto de manifiesta ilegalidad en el Derecho español el artículo 118 de la Ley sobre la Jurisdicción contencioso-administrativa que regula el proceso especial en caso de suspensión de acuerdos de las Corporaciones locales por infracción manifiesta de las leyes, .el 413 de la Ley de Régimen local, regulador de la responsabilidad en que incurren los Secretarios e Interventores de las Corporaciones locales cuando no advierten a las mismas las manifiestas infracciones legales en que pueden incurrir con sus acuerdos, y, sobre todo, el 37 de la Ley de Régimen jurídico de la Administración del Estado, de 26 de julio de 1957, que sustituye el contencioso de lesividad por una revocación administrativa con procedimiento especial cuando los actos que se pretenden revocar infrinjan manifiestamente la Ley.

No pretende este trabajo constituirse en un catálogo de todos los posibles supuestos de manifiesta ilegalidad que se recogen en nuestra legislación administrativa. Aspira tan sólo a examinar los problemas que plantean alguno de estos supuestos, especialmente el del artículo 37 de la Ley de 26 de julio de 1957. Aspira también a construir, en la medida de lo posible, sobre nuestro Derecho positivo, un concepto de acto administrativo viciado de manifiesta ilegalidad, y a enjuiciar si puede tener utilidad la permanencia entre nosotros de una dualidad de trato jurídico para las manifiestas ilegalidades y para las ilegalidades que no tienen tal carácter. 
REVL-1958, núm. 102. CLAVERO AREVALO, MANUEL FRANCISCO. LA MANIFIESTA ILEGALIDAD...

\section{Suspexistón de acuerdos de las Extidades locales POR MANIFIESTA ILEGALIDAD}

El articulo 366 de la Ley de Régimen local establece como caso que justifica la suspensión de los acuerdos de las Corporaciones locales, el que el acuerdo constituya infracción manifiesta de las leyes. Por su parte, el 118 de la Ley de 26 de diciembre de 1956 ha regulado el proceso contencioso-administrativo especial cuando los Presidentes de las Corporaciones o los Gobernadores civiles suspenden los acuerdos de dichas Corporaciones por infracción manifiesta de las leyes.

Como es sabido, el Tribunal Contencioso-administrativo decide en estos casos la anulación del acto, o, por el contrario, que se levante la suspensión del mismo.

Causa de la suspensión administrativa es, en este caso, la manifiesta infracción de las leyes. A este respecto, es conveniente resaltar que no basta con que haya infracción; ésta ha de ser, además, manifiesta, y, además, ha de ser infracción de una concreta fuente de ordenamiento jurídico, cual es la ley. No se da este supuesto, por tanto, según el propio Derecho. positivo, cuando la infracción es de otra fuente jurídica distinta de la ley.

La cuestión consiste en saber si, decretada esta suspensión gubernativa, el Tribunal Contencioso-administrativo puede anular el acuerdo cuando, siendo ilegal o no reglamentario, no constituya, sin embargo, una manifiesta infracción de las leyes. Se trata, por tanto, de saber si en estos casos y procesos el Tribunal puede anular por motivos de legalidad ordinaria, o si sólo puede hacerlo en casos de manifiesta ilegalidad.

Considero que este proceso especial de la Ley de lo contencioso-administrativo tiene por base la manifiesta ilegalidad, y que, por tanto, si el acto no es manifiestamente ilegal, el Tribunal no puede declarar su anulación aun cuando e! acto sea ilegal o no reglamentario. Si ello ocurriera, la anulación del acto debería obienerse a través del proceso contencioso-admi- 
nistrativo común, por quienes estuvieran legitimados para ello, pero en modo alguno a través del proceso especial de anulación del artículo 118 de la Ley citada. Es más, dada la mecánica de nuestro Derecho positivo, puede afirmarse que si el acto administrativo suspendido era ilegal, pero no manifiestamente ilegal, el Tribunal debería levantar la suspensión gubernativa del mismo, por no darse el motivo determinante de tal suspensión, que es tan sólo la manifiesta infracción de las leyes. Creo que si el acuerdo hubiera sido notificado, cosa improbable, dados los cortos plazos de suspensión gubernativa, el plazo para acudir al recurso contencioso-administrativo por los particulares debería quedar en suspenso hasta que decidiera el Tribunal sobre la cuestión de manifiesta ilegalidad. El que éste levantara la suspensión no produciría cantidad de cosa juzgada, en cuanto a la ilegalidad no manifiesta que podria determinar la anulación del acto en la jurisdicción contenciosa: a través del proceso común.

Por cierto que la Ley sobre la Jurisdicción contencioso-administrativa señala que las facultades del Tribunal, al conocer de la suspensión de los acuerdos por manifiesta infracción de las leyes, son la de la anulación del acto suspendido o la de levantar la suspensión recaída. Parece, pues, configurarse este recurso como puramente de anulación. Queda, sin embargo, la incógnita de saber si cuando el acto manifiestamente ilegal lesiona un derecho subjetivo, el particular afectado podría deducir en este proceso especial una petición que entrañara el reconocimiento de su derecho, o tendría que formular tal petición en el proceso común contencioso-administrativo. Hay veces en que la simple anulación de un acto manifiestamente ilegal no sirve para evitar el agravio producido al derecho del particular, y pensar que después de la anulación del acto, a través del proceso del artículo 118, el particular lesionado en su derecho se queda sin justicia y sin acto que recurrir, no deja de resultar una lamentable paradoja. En tal caso, el particular tendria que provocar otro acto administrativo y si de nuevo no se reconocía en él su derecho, tendría que empezar un nuevo recurso contencioso a través del proceso común. Parece, pues, 
aconsejable permitir pretensiones subjetivas en este proceso especial, cuando el acto suspendido fuera manifiestamente ilegal por lesionar o desconocer un derecho subjetivo. Ciertamente que no serán muy frecuentes en la práctica estos casos, pero no por ello debemos dejar de consignar tal posibilidad en un estudio que trata sobre los problemas de la manifiesta ilegalidad de los actos administrativos.

\section{LA ADVERTENCHA DE ILEGALIDAD}

No pretendo estudiar en este apartado todos los problemas de esta curiosa figura jurídica ni tampoco la coyuntura actual de su utilización que tan interesantes cuestiones plantea en el terreno en el que se entrecruzan las misiones de los políticos y el respeto a la legalidad que en sus respectivos campos deben procurar los Secretarios e Interventores de Administración local. Pretendo tan sólo poner de relieve que esta figura singular de la advertencia de ilegalidad constituye otro supuesto en el que cristaliza esta modalidad de la ilegitimidad de los actos administrativos que es la manifiesta ilegalidad.

Es interesante resaltar que según el apartado 2 del artículo 413 de la Ley de Régimen local, el Secretario y el Interventor incurren en responsabilidad si no advierten a la Corporación las manifiestas infracciones legales en que puedan incurrir con sus acuerdos. Parece, pues, que esta especifica responsabilidad de la falta de advertencia de ilegalidad por parte del Secretario y del Interventor sólo se da cuando la ilegalidad es manifiesta. De los restantes apartados del mismo artículo se desprende que Secretarios e Interventores pueden advertir también a las Corporaciones las ilegalidades no manifiestas de los acuerdos que van a adoptar. Así, incluso pueden solicitar quede sobre la mesa hasta la próxima sesión un expediente o propuesta cuando por la indole del asunto tuvieran duda sobre la legalidad del acuerdo. No parece que esta duda en un elemento técnico y especialmente conocedor de la legalidad haga referencia a un supuesto de ilegalidad 
manifiesta. Podrá, pues, discutirse el que ello sea así, pero a la vista del artículo 413 de la Ley de Régimen loca! la responsabilidad específica de los Secretarios e Interventores por no advertir la ilegalidad de los acuerdos que han de adoptarse se concreta tan sólo a los casos en los que la ilegalidad es manifiesta. Aunque el citado precepto habla de manifiestas infracciones legales, ya en este caso no aparece tan clara la referencia a las leyes que se recoge en otros preceptos consagradores de manifiesta ilegalidad, en los que esta figura jurídica se contrae a la infracción de las leyes como fuente primera del Derecho escrito.

De las consideraciones anteriores se desprende la importancia que el concepto de manifiesta ilegalidad tiene para los cuerpos de Secretarios e Interventores de Administración local.

4. La REVOCACIÓN DE ACTOS ADMINISTRATIVOS DECLARATORIOS DE DERECHOS EN CASOS DE MANIFIESTA ILEGALIDAD

La reciente polémica producida en relación con nuestro típico recurso de lesividad ha sido abordada en la Ley de Régimen jurídico de la Administración del Estado con una solución de compromiso que declara precisamente en la manifiesta ilegalidad.

El artículo 37 de la anteriormente citada Ley, dice que: "la Administración no podrá anular de oficio sus propios actos declarativos de derechos, salvo cuando dichos actos infrinjan manifiestamente la Ley, según dictamen del Consejo de Estado, y no hayan transcurrido cuatro años desde que fueron adoptados".

A la vista de este precepto, tenemos que la Administración del Estado no puede revocar sus actos declaratorios de derechos aunque sean ilegales, sino que tiene que acudir al recurso contencioso-administrativo de lesividad. Sin embargo, sí podrá revocar sus actos declaratorios de derechos cuando sean manifiestamente ilegales, según dictamen del Consejo de Estado. No basta, pues, la ilegalidad para que proceda la revocación administratativa, es necesario, además, que la infracción dé una fuente concreta, cual es la ley. No hay. pues, que ponderar la impor- 
tancia que para la revocación de los actos administrativos tiene el concepto de manifiesta ilegalidad.

Se observa que para que proceda la revocación administrativa de los actos declaratorios de derechos que infrinjan manifiestamente la ley, es preciso una formalidad previa, cual es el dictamen del Consejo de Estado en el que se mantenga la existencia de la infracción manifiesta de la ley. Si en el dictamen se admite la existencia de la ilegalidad, pero no la de manifiesta ilegalidad no procederá la revocación administrativa, sino el recurso de lesividad.

De esta manera, si se produce una de estas revocaciones sin dictamen del Consejo de Estado, procederá contra el acto revocatorio recurso contencioso-administrativo. Si se produce la revocación previo dictamen del Consejo de Estado, en el que no se mantenga la' existencia de manifiesta infracción de la Ley, aunque si la de mera ilegalidad, caibrá también recurso contencioso contra el acto revocativo. Finalmente, si se produce la revocación administrativa previo dictamen del Consejo de Estado, en el que se admita la infracción manifiesta de la ley, cabrá también recurso contencioso-administrativo para discutir ante el Tribunal si existía o no manifiesta infracción de la ley. Por cierto, que estimamos que estos casos deberían estar exceptuados de la necesidad de recurrir en reposición antes de acudir a la jurisdicción contencioso-administrativa.

Se plantean también otros problemas interesantes para el caso de que los particulares impugnaran los actos revocatorios ante la citada jurisdicción. El particulai podría suscitar la cuestión de la inexistencia de manifiesta ilegalidad y el Tribunal apreciarla, en cuyo caso procedería la anulación de un acto viciado de incompetencia absoluta. Cabrá incluso discrepancia entre lo dictaminado por el Consejo de Estado y lo decidido por el Tribunal en la sentericia. Se plantea tambièn la cuestión de saber si la Administración demandada podría pretender que se debatiera en el citado contencioso no sólo la cuestión de manifiesta ilegalidad del acto revocado, sino también la de mera ilegalidad ordinaria, lo que seria propio de un contencioso de lesividad. Sería ello casi tanto como admitir una reconvención de la Admi- 
nistración, que como demandada adoptaría una pretensión de lesividad con respecto al acto revocado administrativamente. En buena doctrina, esta' cuestión debemos resolverla manteniendo que el Tribunal en estos casos se limitaría a examinar a existencia de infracción manifiesta de la ley para, en su caso, proceder a la anulación del acto revocatorio. Sería entonces cuando la Administración tendría que declarar la lesividad del acuerdo originado y recurrirlo en vía contenciosa por motivos de ilegalidad ordinaria. Pero ¿y si hubieran transcurrido los cuatro años desde que se adoptó el acuerdo? Contestar esta interrogación en el sentido de que ya la Administración no podría acudir al recurso de lesividad sería tanto como afirmar que la Administración al acudir a la revocación administrativa por manifiesta ilegalidad corría el peligro, si ésta no era apreciada por el Tribunal, de ver cerradas todas las puertas para el examen iurisdiccional de la simple ilegalidad del acuerdo originario. Por otra parte, el que la Administración revocara por manifiesta ilegalidad $\sin$ que hubiera obtenido el preceptivo informe del Consejo de Estado sobre la existencia de una manifiesta ilegalidad, parece también que es una solución harto favorable para la Administración. De aquí que propugnamos como fórmula justa el que se suspenda el transcurso del plazo de los cuatro años a efectos de la declaración de lesividad, sólo cuando hubiera informe del Consejo de Estado en el que se reconociera expresamente la existencia de la manifiesta infracción de la ley. Cuando así ocurra, debería considerarse interrumpido el plazo de los cuatro años desde la iniciación del contencioso, contra el acto revocatorio, hasta la sentencia firme que anulara dicho acto por inexistencia de manifiesta ilegalidad. De esta manera, y en este caso, la Administración podría declarar lesivo el acuerdo originario y poder impugnarlo en vía contencioso-administrativa.

Se observa también en el artículo 37 de la citada Ley que la revocación administrativa por manifiesta ilegalidad de los·actos declaratorios de derechos, no requiere previa declaración de lesividad, sino que basta el informe del Consejo de Estado, en el que se recoja la existencia de la manifiesta infracción de la ley. Sin 
embargo, se mantiene el plazo de los cuatro años para estas revocaciones, que coincide con el que la Administración tiene para declarar lesivos sus actos declaratorios de derechos. Con respecto a este plazo debemos consignar que debiera existir cuando menos una diferenciación de tiempo según la naturaleza del vicio del acto, ya que con el plazo de cuatro años parece descartarse la posibilidad de las nulidades de los actos administrativos que podrían declararse en tiempo muy superior al de los cuatro años. Por cierto, que el párrafo segundo del mismo artículo 37 nos dice que en el plazo de cuatro años podrán rectificarse los errores materiales y de hecho. Aun cuando creemos que no debe seguirse en esta materia la misma solución para los errores materiales y los de hecho, ya que tales vicios de los actos administrativos son de muy distinta naturaleza, podemos afirmar que limitar a cuatro años el plazo de rectificación de los errores materiales resulta un límite muy riguroso, ya que a veces tales errores materiales pueden operar a muy largo tiempo de aquel en que se adoptó el acuerdo.

5. El allanamiento ex la jurisdicción contencioso-adminisTRATIVA

También en la figura del allanamiento en la jurisdicción contenciosa tenemos otro curioso caso donde juega la manifiesta ilegalidad, si bien no de los actos administrativos, sino de las sentencias.

E1 artículo 89 de la Ley de 27 de diciembre de 1956 señala que "allanado el demandado, el Tribunal, sin más trámite, dictará sentencia, de conformidad con las pretensiones del demandante, salvo si ello supusiera una manifiesta infracción del Ordenamiento jurídico o fuese demandada la Administración pública, en cuyo caso dictará la sentencia que estime justan.

Quiere ello decir que en caso del allanamiento del demandado la sentencia será conforme con las pretensiones del demandante, salvo si ello supone una manifiesta infracción del Orde- 
namiento jurídico. Debe hacerse la saivedad de que no estamos en presencia de un caso de manifiesta ilegalidad de los actos administrativos, sino más bien de un supuesto de evitación de una manifiesta infracción del Ordenamiento por una sentencia. Parece, por el contrario, que se permiten, en estos casos, las sentencias que infrinjan el Ordenamiento con tal de que la infracción no sea manifiesta. No parece, desde luego, que ello pueda resultar convincente. Obsérvese también que aquí la manifiesta infracción no va referida a las leyes, sino al Ordenamiento jurídico, que constituye la pieza fundamental de las nueva Ley sobre la Jurisdicción contenciosa, en el que se contienen no sólo la normatividad escrita, sino también los principios generales del Derecho.

Recogemos también en el presente caso esta poco convincente regulación de la manifiesta ilegalidad, aunque en realidad no se refiera propiamente a los actos administrativos.

6. Concepto y juicio de esta modalidad de las ilegalidades ADMINISTRATIVAS

Hemos intentado poner de relieve en este trabajo la existencia en nuestro régimen administrativo de un curioso tipo de ilegalidad de los actos administrativos que adquiere últimamente gran importancia. A la vista de los preceptos que la consagran debemos ahora delimitar el concepto de este tipo de ilegalidad.

Varios de los preceptos que la consagran parecen tipificar estas infracciones como atentatorias a una fuente concreta y específica del Ordenamiento jurídico: la Ley. Tanto el artículo 118 de la Ley sobre la Jurisdicción contencioso-administrativa como el 362 de la Ley de Régimen local hablan de infracción de las leyes. Por su parte, el artículo 37 de la Ley de Régimen jurídico de la Administración del Estado habla expresamente de la revocación administrativa de los actos declaratorios de derechos que infrinjan manifiestamente la ley. No es, sin embargo, tan explícito el artículo 413 de la Ley de Régimen local relati- 
vo a las advertencias de ilegalidad por parte cie Secretarios e Interventores de Corporaciones locales, ya que se limita a consagrar la responsabilidad de tales funcionarios cuando no advierten a la Corporación las manifiestas infracciones legales. La expresión infracciones legales empleada por este precepto no es, sin embargo, tan contundente como la empleada por los otros textos examinados, lo que autoriza a pensar en que quepa en este caso la advertencia por infracción manifiesta de otras fuentes.

Tenemos, por tanto, una característica de la manifiesta ilegalidad en que suele referirse a las infracciones de leyes y no de otras fuentes del Ordenamiento jurídico. Pero no basta con que exista infracción de la ley, para que se dé esta figura es necesario además que tal infracción sea ademós manifiesta. Aquí radica, sin duda alguna, la mayor dificultad para centrar científicamente la definición de este tipo de ilegalidad. Cuándo una ilegalidad es manifiesta y cuándo no lo es. Como se dijo al empezar este trabajo, esta distinción no se identifica con la de ilegalidades que producen nulidad o anulabilidad ni tampoco con la de ilegalidades lesivas y no lesivas para los intereses de la Administración. La distinción entre ilegalidades manifiestas y no manifiestas tampoco puede identificarse con la de infracciones de la ley e infracciones de disposiciones administrativas, porque caben infracciones de la ley que no sean manifiestas.

El carácter de manifiesta en una infracción viene dado porque ésta salte a la vista, sea notoria, se percate sin necesidad casi de un estudio minucioso de los vicios del acto administrativo. Pero este criterio resulta necesariamente vago e impreciso y además, en última instancia, relativo, ya que la notoriedad de la infracción viene referida necesariamente a la mayor o menor idoneidad de los órganos que la enjuicien. Un juez o administrador idóneo necesitará pocos estudios para apreciar la ilegalidad de un acto administrativo, mientras que otro menos avezado sólo podrá pronunciarse sobre tal ilegalidad después de un estudio. De esta manera bien puede deducirse que la manifiesta ilegalidad de un matiz no demasiado preciso y sí bastante vago del que, sin embargo, van a depender muchos intereses de la Administración $\mathrm{y}$ de los particulares. No debemos dejar de ponderar la impor- 
tancia que ha de desempeñar en esta materia la doctrina que se recoja en los dictámenes del Consejo de Estado a que hace referencia el artículo 37 de la Ley de Régimen jurídico de la Administración del Estado.

Nos queda, finalmente, la tarea de enjuiciar el sentido, la necesidad, las ventajas y los inconvenientes que esta modalidad de la ilegalidad de los actos de la Administración tiene en nuestro régimen administrativo.

Nuestra opinión es, desde luego, contraria al trato diferenciado que pretende darse a los actos administrativos viciados de manifiesta ilegalidad. Ello, en primer lugar, porque el criterio diferenciador resulta vago e impreciso como hemos acabado de examinar. El determinar cuándo una 1legalidad es manifiesta y cuándo no lo es y vincular a esta discriminación efectos tan importantes como los que hemos examinado: ofrece serios peligros $\mathrm{y}$ pone a la institución en un terreno movedizo e inseguro. Por otra parte, la idea misma de manifiesta ilegalidad no tiene en sus repercusiones prácticas una tradición en nuestro régimen administrativo.

El hecho de poner el criterio discriminador de la ilegalidad en que ésta sea manifiesta o que no lo sea es fijarse en criterios más aparentes que importantes. Lo verdaderamente importante cuando se produce una ilegalidad no radica en que ésta sea manifiesta o que no lo sea, sino en los perjuicios que la misma produce al buen orden de la Administración y de sus actividades o a los intereses y derechos de los ciudadanos. Puede haber ilegalidades no manifiestas que, sin embargo, engendren enormes perjuicios para la Administración o para los particulares. En todo caso no debe ser la nota de manifiesta, la que debe justificar una diversidad de régimen jurídico para la ilegalidad de los actos administrativos. Ello supone mirar más a las apariencias que a los efectos de la ilegalidad, que es lo verdaderamente importante. De aquí que nos parezca justificado el dar un tratamiento jurídico desigual a los actos administrativos por el carácter manifiesto de la ilegalidad en que puedan incurrir.

Cuestión distinta es la de hacer depender el concepto de manifiesta ilegalidad, no sólo del carácter manifiesto de la ilegali- 
dad, sino también de la naturaleza de la norma infringida. Hemos visto cómo en nuestro régimen administrativo la manifiesta ilegalidad suele producirse precisamente cuando la norma infringida tiene el rango de ley. Podria pensarse que la manifiesta ilegalidad se daría cuando el acto infringe la ley y además en forma manifiesta. De esta manera, esta clase de ilegalidad tendría un tratamiento distinto de otras ilegalidades, precisamente en razón del rango de la fuente normativa violada. Frente a las infracciones manifiesta de la ley tendríamos infracciones de las disposiciones administrativas o de otras fuentes jurídicas. Aun cuando reconozcamos que este matiz diferenciador puede ofrecer más fundamento para justificar el diverso trato jurídico que se da a las manifiestas ilegalidades, creemos, no obstante, que no resulta convincente.

Ciertamente que no es lo mismo infringir una ley que un reglamento, pero en ocasiones la importancia de una infracción puede resultar de más gravedad si se ha violado un reglamento en vez de una ley. Por otra parte, habría que calificar a estos. efectos las infracciones de leyes fundamentales, de leyes ordinarias, de Decreto-leyes, de leyes delegadas, etc. Habría también. que determinar si las infracciones de los principios generales del Derecho se incluían o no en los supuestos de manifiesta ilegalidad. Por este camino podría llegarse a establecer todo un catálogo de diversas ilegalidades de los actos administrativos, según la fuente infringida de las que componen la jerarquía de las fuentes en el Derecho administrativo. Por otra parte, la distinción entre las ilegalidades de los actos administrativos basada en la distinción entre infracción de la ley e infracción de disposiciones administrativas, podría tener un relativo y discutible fundamento en los Estados de separación de poderes y si se quiere también en los regímenes parlamentarios, pero en modo alguno de los de concentración de poderes.

Creemos, por tanto, que el camino más exacto para determinar los distintos efectos de las ilegalidades de los actos administrativos no puede ser otro que el del examen de los vicios de cada uno de los elementos del acto y no del rango de las normas infringidas. Este último aspecto sólo podria tener cierta rele- 
vancia en los vicios de algún elemento concreto de los actos administrativos, pero no por via general.

Para terminar, podemos decir que el requisito de que la ilegalidad sea manifiesta para dar a los actos que adolezcan de tales vicios un tratamiento jurídico especial no parece convincente. Mayor interés puede suponer el pretender hacer de la manifiesta ilegalidad de los actos administrativos una categoría de ilegalidad determinada por rango de ley de la norma infringida. No obstante, parece. más útil el determinar los distintos efectos de las ilegalidades de los actos administrativos a través del examen de cada uno de los vicios de los elementos de dichos actos. 